\title{
Trends in the global marketing of white clover cultivars
}

\author{
R.D.J. MATHER, D.T. MELHUISH and M. HERLIHY \\ Wrightson Seeds Limited, PO Box 939, Christchurch
}

\begin{abstract}
White clover (Trifolium repens L.) is the dominant legume of temperate pastures, having been improved by breeding since the 1930s. The 1994 OECD Register lists 93 cultivars, with a further $25-30$ cultivars also known to commerce. Therefore, in excess of 100 cultivars are available to fulfil a world annual market of 8500-10,500 MT. Globally, New Zealand is the major white clover production region, providing 50 $55 \%$ of the seed. Other key production regions are Denmark, USA and South America. Consumption of white clover has been relatively static for some time, ranging from 8000-10,000 MT per annum. Between $55-60 \%$ of the seed is used in the northern hemisphere (approx. 40\% by Western Europe - UK, France, Germany). USA, South America and New Zealand all consume similar tonnages annually (approx. 1000-2000 MT each) with smaller tonnages used in Australia. One cultivar, Grasslands Huia, has dominated the world white clover seed market for many years and it still remains the world's major cultivar by volume. However, in the last 10 years its position has come under increasing pressure from New Zealand and international proprietary cultivars. Eventually proprietary cultivars with improved agronomic performance will supersede the consumption of commodity/public white clovers in those countries where national listing is required to obtain release and recommended listing is need to ensure successful marketing. Despite this, Grasslands Huia will continue for many years to play a major role in supplying markets where national listing is not a prerequisite to release and price is a major factor in purchase decisions.
\end{abstract}

Keywords: commodity cultivar, global market, Grasslands Huia, leaf size, market share, production trends, proprietary cultivar, seed industry, Trifolium repens L., white clover

\section{Introduction}

White clover is recognized as the most valuable legume species in New Zealand grassland systems due to its contribution as a complementary component in a grass sward, its highly nutritive feed value and long seasonal growth. It is an economic source of Nitrogen and its role in pastures is undisputed.
White clover is also synonymous with New Zealand's standing and reputation as a leading producer and exporter of temperate pasture seeds for world markets. White clover has given the New Zealand seed industry its international profile.

The combination of maritime climate, geographical location, unique farming systems, and competent growers have provided the key elements that have positioned our country as the leading exponent in the world supply of white clover. The challenge ahead of our industry is to maintain this competitive edge in an ever changing market place.

In compiling this paper on marketing trends we have by necessity recognized that there is a lack of international statistics on production and consumption of this species We have used statistics where available and have also blended in information and comments from many associates throughout the world in support of our assumptions.

We have also surveyed a number of commercial organizations to assess their thoughts on future trends for white clover in various markets. It must be accepted that this paper has been prepared from a commercial perspective given the facts and information available.

\section{Role in agriculture}

The valuable contribution of white clover as a forage for livestock production has been recognized for centuries. It is believed that the early cultivation of white clover can be traced back to the Netherlands in the 1600s and introduced into England in the 1700s. White clover seed followed the early settlers to New Zealand and immediately displayed adaptability to its new environment.

White clover is one of the most nutritious and widely distributed forage legumes in the world and has shown its main adaption within the temperate zones. On a world scale, the optimum performance of white clover as a pasture plant occurs in the mild and temperate climate of north west Europe and New Zealand.

The role of white clover as a component of a pasture has been best demonstrated under the varied farming systems practised in New Zealand. From the harsh highlands of the South Island, to the lush pastures of the Waikato, white clover has proved to be a most adaptable and persistent legume especially when introduced to intensive and heavy grazing. 
Natural selection over time, recently assisted by plant breeders, has segmented the species into distinct leaf sizes that has expanded the usefulness of white clover. Small leaf types are utilized best in hard grazing situations where persistence is important. Large leaved Ladino types are more suited for lax grazing but with an adaptability which has allowed the species to reach into sub tropical regions. By far the largest usage of the species has been for the intermediate leaf type ideally represented by Grasslands Huia white clover.

Plant breeders have recognized the need for continued segmentation of white clover and consumers now enjoy an ever growing range of cultivars with specific leaf size and other agronomic attributes which meet real and perceived market niches and opportunities.

While white clover is rated as the major pasture legume in New Zealand, UK, Ireland and Denmark, alfalfa and red clover are considered more important in western and southern Europe, USA and South America. Alfalfa and sub clover are the dominant species used in Australia.

White clover has a limited use for turf purposes and during flowering is considered a desirable plant for the production of honey.

\section{The global market}

The annual global production of white clover is estimated to be between 8500 to $10,500 \mathrm{MT}$ (av. $9500 \mathrm{MT}$ ). New Zealand is the major production region providing approx 45 to $50 \%$ of this seed. Other key production regions are Denmark, USA, Uruguay/Argentina and Australia.

On a hemisphere basis, approx. $70 \%$ of this seed is produced in the southern hemisphere, the balance equally shared between Denmark and the USA. One area that is difficult to quantify is the tonnage of uncertified seed that is produced and traded outside the traditional wholesale seed network. This trade would be prevalent in the USA and South America. We have taken an estimation of the size of this market in our assessments.

From a global perspective, white clover would rate on volume basis as the world's third key pasture legume, well behind alfalfa $(160,000+$ MT) and red clover $(15,000+\mathrm{MT})$. Consumption of white clover ranges between 9000 to 10,000 MT. Approximately 55\% to $60 \%$ of seed is used in the northern hemisphere with the major consuming regions being Western Europe (i.e. UK, France, Germany) and USA.

South America, North America and New Zealand all consume similar tonnages (approx. 1,000 to 2,000 MT each annually) with smaller tonnages used in Australia (approx. 600 MT). Other areas of regular consumption include Japan, China and South Africa.
We suggest that consumption globally has been relatively consistent on average over the past 10 years. At any stage during a year between 500 to 1000 MT of white clover is considered "carry over stock". Carry over stock is adjusted over time by the law of supply and demand and the influence this has on grower value.

The weather leading up to and during harvest plays a major role in determining crop yield. While consumption is also influenced by weather, especially at sowing, other driving forces such as a rise or decline in livestock values, prices of alternative pasture legumes, set-aside programmes, environmental issues and the general agricultural outlook all have a major influence on seed usage.

With the majority of white clover seed being produced in the southern hemisphere dominated by New Zealand, and the major usage being in the northern hemisphere, the New Zealand market is naturally sensitive to the agricultural economy and prevailing environmental factors in key consumption regions. These factors in turn dictate the value of New Zealand white clover. For example, the large projected 1995 crop in Denmark along with the current carry over of Danish cultivars from their 1994 crop is reflected in an easing in value for Huia at this present time (Figure 1).

The white clover market is segmented by way of leaf size. The major share being for intermediate types (i.e. Huia) with larger leaf types gaining in popularity. Small leaf cultivars have an important but minimal market share (Figure 2).

\section{White clover in New Zealand}

White clover has always been a key pasture species in New Zealand. Following its introduction by the early settlers in the 1800 s, the species immediately adapted to New Zealand's environment. Its performance was quickly recognized and seed was soon being produced locally by entrepreneurial farmers.

Table 1: Key white clover events in New Zealand.

1928 Introduction of Certification for white clover (i.e. New Zealand certified seed).

1935 New strain of white clover released by DSIR. This became certified New Zealand white clover.

Permanent pasture (PP White Clover introduced)

1964 Grasslands Huia white clover released

1969 Trial multiplication of European cultivars first undertaken.

1975 Grasslands Pitau white clover released

1982 Grasslands Tahora white clover released

1985 First commercial multiplications of European cultivars undertaken

1987 Permanent Pasture white clover discontinued

(pers. comm. D. Eaden) 
Figure 1:

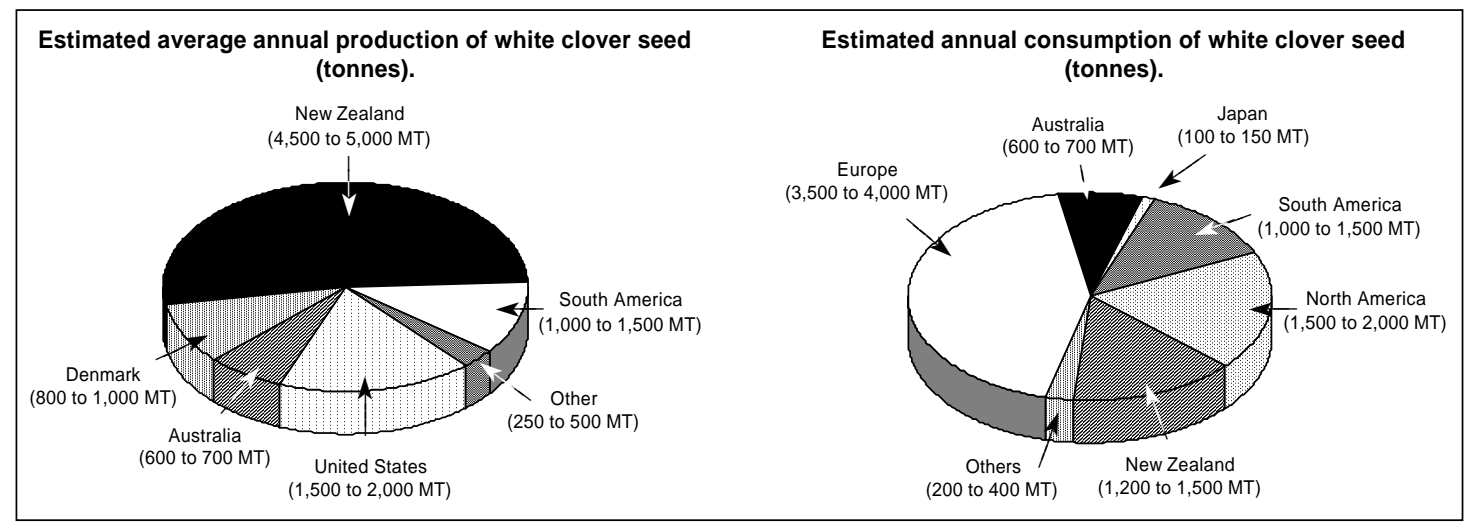

Early market reports show a fascinating trend. In 1914 white clover was available with values ranging $17 \mathrm{c}$ to $20 \mathrm{c}$ per $\mathrm{kg}$. In 1920 the species was scarce with values as high as $45 \mathrm{c} \mathrm{kg}$. In 1925 markets were dead due to cheap importation from England with values back to $22 \mathrm{c}$ to $25 \mathrm{c}$ per $\mathrm{kg}$. In the 1930 s white clover was in good demand and by 1940 the value reached $65 \mathrm{c}$ per $\mathrm{kg}$. This price was too high for the New Zealand market therefore the majority of seed was exported to England (PGG Annual Reports). In 1945 demand was high, and machine cleaned seed, no matter what origin, was accepted for certification if it was dressed by a registered cleaning plant, with values $\$ 1$ to $\$ 1.05$ per $\mathrm{kg}$. In 1950 a crop of 6500 hectares was entered for certification and in 1952 a record crop of 5000 MT was harvested from 25,800 hectares. Of this crop 3570 MT was exported to UK and USA. Values declined during this year from $65 \mathrm{c}$ to $45 \mathrm{c}$ perkg. By 1955 the crop had receded to 2000 MT from 9200 hectares and values fluctuated from an opening price of $\$ 1$ to a high of $\$ 1.60$ closing at $\$ 1.20$.

It is apparent from these old records, especially when compared with later statistics, that over the years in New Zealand, white clover production and sales have varied considerably both in value and volume. Both demand and seed yields finally influencing values (Figure 3).

Looking back 30 years; 34,000 hectares were under production with an estimated crop of $4000 \mathrm{MT}$ produced from two cultivars. Today's crops of 4000-5000 MT are produced from about twenty cultivars off 15,000 hectares. This upward trend in seed yield per hectare over the past 30 years has enabled New Zealand to maintain volume production from a declining production area.

Due to its adaptability, performance, availability and price competitiveness, one white clover cultivar
Figure 2:

\section{Estimated market share of white clover by leaf size}

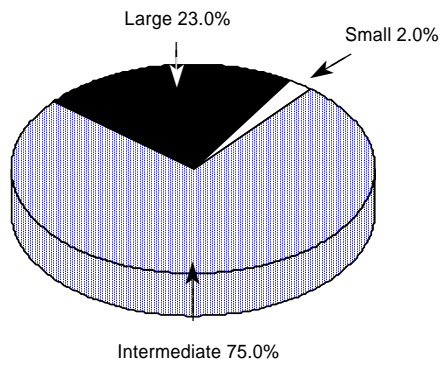

(Grasslands Huia) has dominated world markets. It remains the world's major cultivar by volume (35\% to $40 \%$ ). While its position in world markets is now coming under pressure from proprietary releases (in many instances produced in New Zealand), its importance and position in the world market will ensure Grasslands Huia will continue to play a major role for some time.

New Zealand has a world recognized position in breeding, producing, and marketing white clover. The challenge ahead is to maintain this edge, and maximize the unique circumstances that we have in New Zealand. New Zealand cannot afford to build its industry on the ability to produce seed alone. Cultivars must be bred that will meet the future demands of world markets, and New Zealand must be ready to produce and supply this seed.

\section{Commodity vs proprietary}

In reality this heading should read public vs proprietary cultivars as there is only one recognized commodity 
Figure 3: Annual production of white clover seed compared to hectares grown in New Zealand.

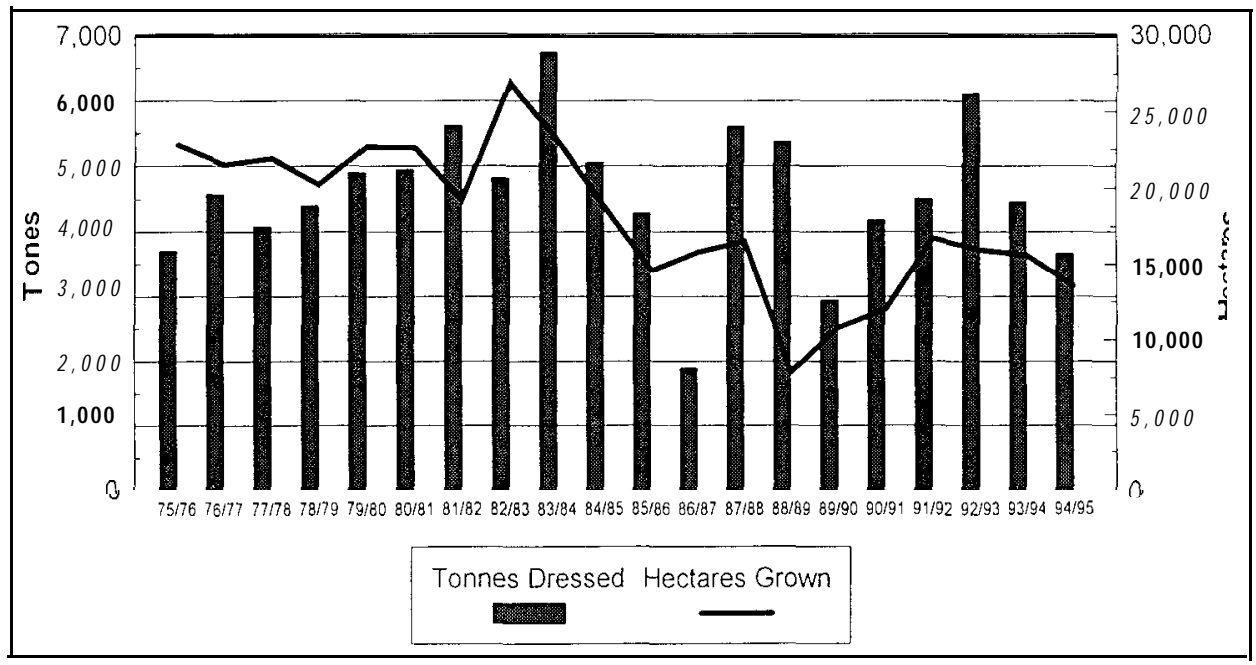

white clover, Grasslands Huia. A commodity by definition is an exchangeable unit of economic wealth (Collins Dictionary) and in the seed industry Grasslands Huia ideally exemplifies this. Units of Grasslands Huia (normally container lots) are freely traded on the international market from either present or future crops by companies with an interest either in covering their requirements or by speculators who like to indulge in such markets. Complementing Grasslands Huia in the public arena are some cultivars that are freely traded primarily within their home markets (e.g. Grasslands Pitau). These are also exported to various markets but they are not used or recognized to the same degree for speculation.

The market place has been dominated by commodity/ public cultivars, but over the past 10 years, proprietary cultivars have made inroads into the dominance of public cultivars, especially in markets such as the UK and New Zealand.

For the European market, the major requirement in Northern Regions is for intermediate leaf types while intermediate and larger leaf types are required in southern Europe. New Zealand and Denmark are the primary suppliers of seed. The Danes, with the cultivars Milka and Milkanova, consider Grasslands Huia their major competitor and there is a strong relationship between the supply and value of Danish white clover and the uptake and value of Grasslands Huia into Europe. Milka and Milkanova are considered proprietary cultivars and normally command a premium over Grasslands Huia in the market place, while growers also enjoy the benefits of EU subsidies on their crop. The Danish crop is only about $20 \%$ in volume compared to New Zealand (Figure 4).
Figure 4: New Zealand and Denmark white clover seed production fluctuations.

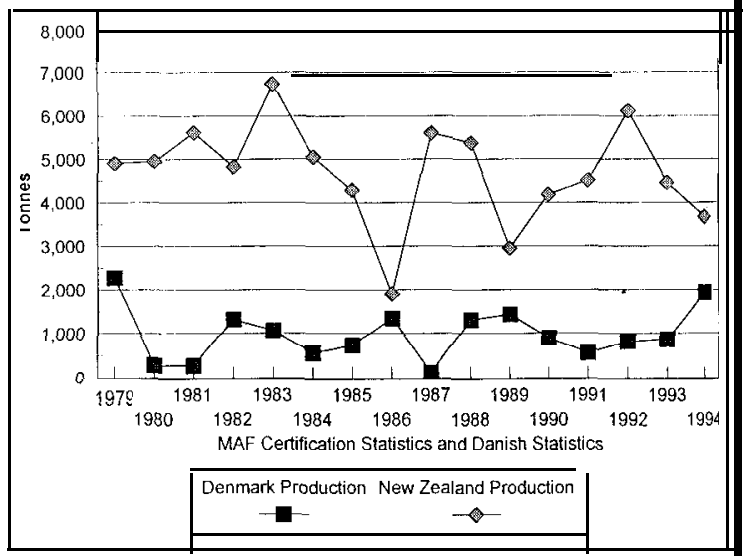

AVERAGE LAST 5 YEARS

White clover consumption in Europe Huia exports to Europe Other white clovers exported to Europe from New Zealand

The influence of Plant Variety Rights and national testing requirements in Europe focused the attention of UK and European plant breeders to the development of improved cultivars for specific market niches primarily within their home markets.

In New Zealand back in the 1970s, DSIR Grassland's breeding philosophy for white clover was to produce cultivars that would enhance New Zealand's pastoral 
based industries. Little focus was given to the development of cultivars aimed at offshore markets to support the production infrastructure that had developed for the species.

The Welsh and Irish Plant Breeding Stations had been active in white clover breeding, along with other European breeders, and began making a series of releases in the early 1980s. These releases not only challenged the dominant position of Grasslands Huia in Europe, but also segmented the market with improved cultivars, bred specifically for European testing systems and European farming methods. These releases encompassed mainly the intermediate (e.g. Menna) to large leaf types (e.g. Aran).

These cultivars established themselves on various recommended lists within the EU. The principal parties then had to look to countries, such as New Zealand, for production. As the production of preferred cultivars increased, the strategy was, that the requirement for public cultivars (e.g. Grasslands Huia) into European markets, would decrease. To date the only area to show a significant reduction in the uptake of Grasslands Huia has been the UK where exports have declined $50 \%$ over the past 10 years.

Figure 5: Grasslands Huia white clover exports to Europe.

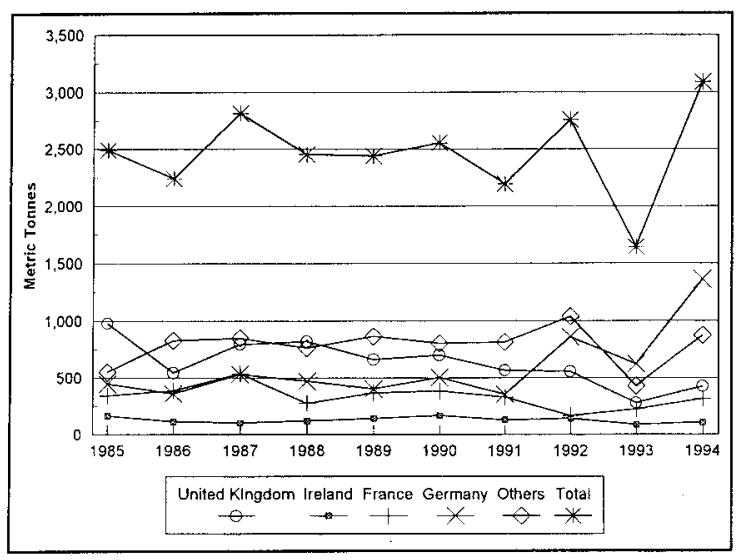

Proprietary cultivars showing improved agronomic performance and demonstrated cost/benefits, will, overtime, supersede the consumption of public white clovers in those countries where national listing is necessary to obtain release, and recommended listing is required to ensure success in marketing and in other markets that could be described as mature (i.e. New Zealand).

Even in countries that do not require national listing, proprietary cultivars are beginning to gain incremental market share as consumers recognize the benefits available. This is most evident in New Zealand (i.e. proprietary market share $35 \%$ to $40 \%$ ) and Australia $(10 \%$ to $15 \%)$ with the uptake over recent years of new improved releases especially from Grasslands (i.e. Kopu, Tahora, Prestige, Demand). Availability of these releases is probably restricting greater market share. In the USA and South American countries there is now an awareness and uptake of improved proprietary material. The demand for proprietary cultivars is driven by actual or perceived improved performance and the desire on the part of many seed marketing companies to have an exclusive cultivar within their portfolio.

Where national listing is not a prerequisite to release, and price is a major factor in the purchase decision (e.g. USA) then public white clovers will continue to have market acceptance for many years to come. Grasslands Huia due to its position as the dominant commodity white clover, will have a significantly longer life span than other public cultivars.

There are now moves to require cultivars to be inscribed on National Lists prior to marketing in countries such as Chile and Argentina. Inscription should not be confused with the extensive testing required for listing into the E.U.

The present production of preferred proprietary cultivars seems unable to satisfy existing demand. Until this can be achieved, public cultivars (e.g. Grasslands Huia) will continue to enjoy a major share of the global market. Often public cultivars are blended with proprietary types to lower costs which indicates that "price" is still a sensitive factor in the positioning of cultivars even in mature markets (e.g. Europe)

In areas such as North and South America and Australia, where white clover is used in extensive grazing situations, price will remain an important issue. In these regions commodity/public cultivars will continue to be used in volume. High performing proprietary cultivars will forge some market share, especially in situations requiring and affording higher inputs (e.g. dairy) or in regions requiring specific agronomic characteristics such as improved drought tolerance and persistence, as demonstrated by Grasslands Tahora.

The challenge for New Zealand is to breed and produce in volume, cultivars that can establish themselves globally but importantly within the restrictive markets of the E.U. due to its dominance as the major consumption region. These cultivars will need to perform in national and recommended list trials, and in other key consuming regions where the market will pay for improved performance. New Zealand's competitive edge will be further enhanced if cultivars adaptable to the E.U. also find solid market acceptance in New Zealand and other areas. This allows flexibility in marketing and 
reduces the risk associated with only producing for a single market.

Recently both Grasslands Tahora and Grasslands Demand obtained national listing in the UK with Grasslands Demand also gaining provisional recommendation in the UK. Both have good market uptake in New Zealand and other countries and therefore are not exposed to the same extent of supply/demand risk that would occur if they were targeted towards a single market.

The advent of proprietary marketing and the complexity and competitiveness of today's market place would suggest that there is little likelihood of any breeder developing another cultivar that will dominate the market to the extent of Grasslands Huia. New Zealand growers are well placed to take full advantage of the movements in cultivar demand, and should maintain dominance in world production. This will over time require a shift away from Grasslands Huia production to that of the preferred cultivars. Growers however need some comfort, that the cultivar they will grow, will have longevity in its life span and that values fully compensate for the extra production responsibilities. Growing only for a re-export market can leave growers vulnerable to the supply and demand situation in that region where maybe they have little understanding.

Another plus in New Zealand developing cultivars for world markets, is the generation of significant royalties which will in turn contribute towards future breeding programmes. It is estimated that if we replaced current European cultivars being grown in New Zealand with New Zealand bred material for export it would generate approximately $\$ 250,000$ in royalties annually for our country.

\section{Market satisfaction}

Throughout the world the usage of white clover is considered to be static, or at best, has only small growth in volume uptake. An increase in uptake could be projected for Australia, USA and South America as improved proprietary cultivars gain a share within specific niches and expand the market. This increase may be offset by a decline in uptake in the E.U. and Japan due to receding areas used for pastures. Unfortunately we cannot predict political decisions, such as major projects in developing countries, set-aside programmes or environmental decisions, all of which may change projections.

Given the number of cultivars now available it could be considered there are more than sufficient to meet present demands. AgResearch have a list of 319 known cultivars (Caradus \& Woodfield 1996) while the OECD register (1994) lists 93 cultivars. A further 25 to 30 cultivars are known to be currently in commerce outside the OECD List. This makes a total, in excess of 100 cultivars in the system, to fulfil a market of 8000 to $10,000 \mathrm{MT}$, of which more than $50 \%$ is obtained from three cultivars (Grasslands Huia, Milka, Milkanova). However, we participate in a world driven by commercial expectancy and the desire to secure a share of a market, often regardless of cost.

Breeders will continue to develop new material, releasing on average 7 new cultivars annually (Caradus $\&$ Woodfield 1996). This may segment existing market streams, or add new and improved agronomic characteristics, or it may just bring forward material that offers little by way of agronomic advancement, but will, by sheer promotional pressure, obtain a market share. In many instances new releases will not expand the usage of proprietary material (e.g. replacing public cultivars) but will compete for share in the higher input areas currently serviced by other proprietary cultivars. There will be little justification for the current input into white clover breeding globally if breeders and marketers do not focus on a strategy to replace the use of public cultivars with improved proprietary material.

The market place will eventually decide how many cultivars can co-exist. The most important consideration will be the ability to obtain consistent and reliable seed production to back agronomic improvements. From a growers perspective, seed yield will be an important criteria in the breeding process, and from a marketer's perspective, the production and sale of enough volume over time to meet the breeding and development costs of a new cultivar, will be essential. The level of volume requirement will be commensurate with the required return on the investment.

We also suggest that market acceptance of a new white clover takes some time to achieve ( 3 to 5 years) after commercial release, unlike a ryegrass that can quickly demonstrate its attributes.

In surveying the market place the following desirable characteristics were suggested for future releases in order of importance.
Improved persistence
$>$ Increased dry matter yield
$>$ More competitive in sward situation
$>$ Added stolon density
$>$ Extended climatic suitability
$>$ Improved disease resistance
$>$ Higher digestibility
$>$ Competitive seed yield.

The development of improved intermediate to larger leaved cultivars have the greatest market appeal followed by specifically large leaf types. Further small 
leaved cultivars have the lowest global market interest.

Genetic modification is recognized as having major importance for future breeding objectives and while the market place may accept modified cultivars there is the question if downstream industries will accept agricultural products produced from genetically modified pasture plants.

The three key factors for the successful life span of a new cultivar would seem to be:

Offer specific agronomic performance

$>$ Readily and consistently available

$>$ Be price competitive.

\section{Forces affecting marketing}

\section{Plant variety rights}

Various plant protection legislation serves only to protect the intellectual property of the breeder, it does not detract or improve the usage of white clover into the markets where such protection exists.

\section{$\boldsymbol{G A T T}$}

The success of the GATT Uruguay round, which heralds in the reduction, over time, of tariff protection and production and export subsidies, should aid the flow of white clover between producing and consuming countries.

While the elimination of tariffs into markets such as Europe (current tariff on Grasslands Huia white clover $2 \%$ ) will assist the buyer, it is doubtful they will in turn lead to greater consumption of seed.

\section{Testing systems}

While the testing procedure into Europe may seem bureaucratic, restrictive and lengthy from a New Zealand perspective, we must accept the need to develop cultivars that will succeed within the system. Testing systems as a requirement for import entry or inscriptions onto national certification or national or regional recommended lists seem to be on the increase. Testing systems impose, in most cases, a temporary restriction to marketing and in the longer term can make or break a cultivar.

\section{Phytosanitary requirements}

Border protection, through the use of phytosanitary requirements, could play a role in restricting the flow of white clover into specific markets. To date, the quality and high standard of New Zealand produced seed has provided little opportunity to invoke any restrictions. New Zealand as a producing region, must be mindful of the key role phytosanitary requirements will play in the future.

\section{The environment}

World-wide pressure to put right the environment does have a positive flow down on white clover uptake. Setaside programmemes, the reduction of artificial nitrogen, organic farming and the adoption of a general "Green Image" in the western world all look towards a natural answer to environmental issues. In many cases the usage of white clover can provide an acceptable remedy.

Set-aside programmemes and environmental issues tend to be politically motivated and the uptake and usage of seed within such programmemes can fluctuate significantly from year to year.

\section{Production}

By far the major key issue in expanding the marketing of proprietary white clover cultivars will be in the ability to have adequate and consistent seed production to meet the demand. Alternative land use options in key production regions are reducing the land availability for white clover production. Dairying, processed vegetable production and life style farming activities in the Canterbury region of New Zealand, are contributing towards this.

We are aware that many European companies have sought to produce their cultivars in other production regions. To date seed yields from crops in USA, Argentina and Australia have not proved consistently reliable.

New Zealand basically holds the key to the future of white clover as a key pasture legume. Therefore, over time, we must look to encourage growers to change away from Grasslands Huia white clover to preferred cultivars. To achieve this, we need to look closely at existing certification criteria and question if this is now appropriate. To satisfy OECD requirements we only need 3 years between different cultivar plantings. If we can overcome buried seed contamination, then the three year requirement should be adopted.

\section{Summary}

Without significant political interference, there is nothing in our investigations to suggest that the global uptake of white clover will shift significantly $(+$ or - ) over the next 5 years. Commodity white clover, especially Grasslands Huia will have a major influence on the market place until preferred proprietary cultivars can be produced in volume to meet demand. This can only occur as Grasslands Huia is phased out of production.

New Zealand is the key production region in the world and will remain so for many years. Our challenge must be to breed and produce cultivars that can succeed in all key consumption markets. As proprietary cultivars 
gain production volume and market acceptance, the variations in volume and value will even out.

Production values to growers must keep pace with alternative land options. Consumers will have to pay more for seed and this in turn may affect consumption temporarily. The target market, for future proprietary releases, is the dominant portion of the market currently held by commodity/public cultivars. Future proprietary releases must exhibit significant advantages in agronomic and seed yield potential to command a commercially acceptable market share. Market recognition and subsequent seed uptake takes longer for white clover than alternative pasture species (e.g. ryegrass) as users accept benefits.

\section{References}

Caradus, J.R.; Woodfield, D.R. 1996. World checklist of white clover varieties II. New Zealand Journal of Agricultural Research (submitted). 